\title{
Performance Analysis of an Atkinson Cycle Engine under Effective Power and Effective Power Density Conditions
}

\author{
G. GONCA*
}

Yildiz Technical University, Naval Arch. and Marine Eng. Depart., Besiktas, Istanbul, Turkey

(Received November 16, 2016; in final form May 20, 2017)

\begin{abstract}
This study presents performance optimization of an Atkinson cycle engine using criteria named as effective power and effective power density conditions. The effects of design and operating parameters such as compression ratio, cycle pressure ratio, cycle temperature ratio, equivalence ratio, bore/stroke ratio, inlet temperature, inlet pressure, engine speed, friction coefficient, mean piston speed and stroke length, on the performance characteristics have been examined. Moreover, the energy losses have been determined as fuel energy and they have been classified as incomplete combustion losses, friction losses, heat transfer losses, and exhaust output losses. Realistic values of specific heats have been used depending on temperature of working fluid. The results of the study can be assessed as an engineering tool by the Atkinson cycle engine designers.
\end{abstract}

DOI: 10.12693/APhysPolA.132.1306

PACS/topics: gasoline engine, Atkinson cycle, engine performance, power density, finite-time thermodynamics

\section{Introduction}

In the recent years, the researchers carried out several studies [1-21] on the Miller cycle (MC) engine to diminish NOx emissions by reducing the maximum combustion temperatures of the engines. However, the Atkinson cycle (AC) engine can provide more cycle work than the Otto cycle (OC) engine and the Miller cycle (MC) engine at the same maximum combustion temperatures due to higher expansion ratio. Therefore, so many works have been performed about $\mathrm{AC}$ engines in the recent years. Wang and Hou [22] analyzed the performance of an AC engine using maximum power and maximum power density criteria. Ge et al. [23] determined the performance of an $\mathrm{AC}$ engine with considerations of heat transfer losses, friction losses and temperature dependent specific-heats of the working fluid. Lin and Hou [24] conducted an investigation about the effects of heat loss, friction loss, and temperature dependent specific heats on the performance of an air-standard AC engine under the restricted maximum cycle temperatures.

Benajes et al. [25] investigated the potential of the AC and exhaust gas recirculation (EGR) applications on reducing of exhaust emissions in a heavy duty diesel engine. It was pointed out that $\mathrm{AC}$ can remarkably decrease nitrous oxides but soot emissions increase. Ebrahimi [26] examined the influences of the equivalence ratio, average piston speed and temperature of cylinder wall on the performance of an AC engine using a finite-time thermodynamics (FTT) model. Zhao et al. [27] performed an optimization work for geometrical compression ratio and operating parameters of an $\mathrm{AC}$ spark ignition engine based

*e-mail: guvengca@gmail.com on artificial neural network technique. Gahruei et al. [28] compared the performances of dual Diesel cycle and dual $\mathrm{AC}$ based on the FTT by considering irreversible energy losses. It was observed from the results that the performance of dual AC are higher than that of dual Diesel cycle. Zhao and $\mathrm{Xu}[29]$ designed an $\mathrm{AC}$ engine in order to maximize fuel economy at partial load running conditions based on genetic algorithm and power simulation models. The results showed that the fuel economy could be improved up to $7.67 \%$.

Mozaffari et al. [30] conducted an optimization work for the $\mathrm{AC}$ engine using mutable smart bee algorithm and adaptive neuro-fuzzy inference system. Capaldi [31] designed a novel Atkinson-Miller cycle engine for a micro cogeneration plant to increase thermal efficiency of the plant and to abate the pollutant emissions released from the plant. Gonca and Sahin [32] carried out a thermo-ecological performance optimization for a dual $\mathrm{AC}$ engine. Gonca $[33,34]$ performed a couple of investigation studies on the dual $\mathrm{AC}$ engine considering friction, heat transfer and temperature-dependent specific heats based on classical thermodynamics and FTT methods. Ebrahimi [35-37] carried out thermodynamic performance analyses for the dual cycle [35], MC [36] and AC [37] engines.

In this study, the influences of the design and running parameters on the efficiency, power and power density of an $\mathrm{AC}$ engine have been examined by using simulation model based on the FTT. In this comprehensive report, performance conditions have been evaluated based on the effective efficiency (EE), effective power (EP), and effective power density (EPD) for an AC engine. This study has a noticeable novelty. Presented results can be assessed by engine designers and manufacturers to obtain optimum performance conditions for the $\mathrm{AC}$ engines. 


\section{Theoretical model}

In this study, AC engine is analyzed by using FTT model. The AC is shown in Fig. 1. The parameters and engine specifications used in the analysis are inlet pressure $P_{1}$, inlet temperature $T_{1}$, engine speed $N$, stroke $L$, bore $d$, residual gas fraction (RGF) friction coefficient $\mu$, cylinder wall temperature $T_{W}$, cycle temperature ratio $\alpha$ and their standard values are given as follows: $100 \mathrm{kPa}$, $300 \mathrm{~K}, 3600 \mathrm{rpm}, 0.072 \mathrm{~m}, 0.062 \mathrm{~m}, 0.05,12.9 \mathrm{~N} \mathrm{~s} / \mathrm{m}$, $400 \mathrm{~K}, 8$, respectively. In the present model, the EE, EP,

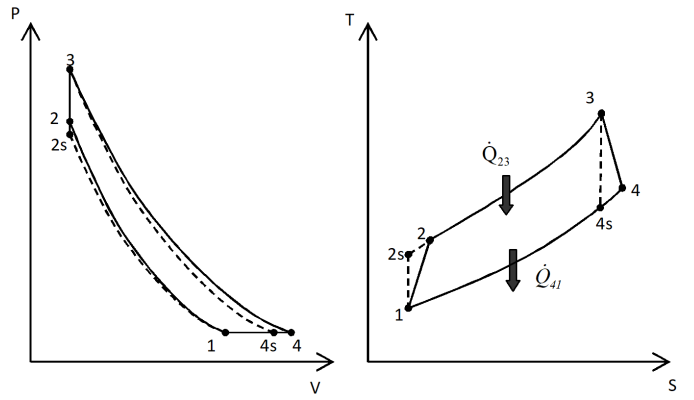

Fig. 1. $P-V$ and $T-S$ diagram for the irreversible Atkinson cyclediagram for the irreversible Atkinson cycle.

and EPD are given as below [19, 20, 33, 38]:

$$
\begin{aligned}
& E E=\eta_{e f}=\frac{P_{e f}}{\dot{Q}_{f}}, E P=P_{e f}=\dot{Q}_{i n}-\dot{Q}_{o u t}-P_{l}, \\
& E P D=P_{d}=\frac{P_{e f}}{V_{T}},
\end{aligned}
$$

where the total heat addition $\left(\dot{Q}_{i n}\right)$ at constant volume $(2-3)$, the total heat rejection $\left(\dot{Q}_{\text {out }}\right)$ at constant pressure $(4-1)$ and loss power by friction $\left(P_{l}\right)[10,39]$ could be written as below:

$$
\begin{aligned}
& \dot{Q}_{\text {in }}=\dot{Q}_{f, c}-\dot{Q}_{h t}= \\
& \dot{m}_{T} \int_{T_{2}}^{T_{3}} C_{V} \mathrm{~d} T=\dot{m}_{T}\left(0.835 \times 10^{-11} T^{3}\right. \\
& \quad+0.5816 \times 10^{-7} T^{2.5}-2.123 \times 10^{-7} T^{2} \\
& \quad+2.108 \times 10^{-5} T^{1.5}+1.0433 T+2.024 \times 10^{4} T^{-0.5} \\
& \quad-3.063 \times 10^{5} T^{-1}+1.106 \times\left. 10^{7} T^{-2}\right|_{T_{2}} ^{T_{3}}, \\
& \quad \dot{Q}_{\text {out }}=\dot{m}_{T} \int_{T_{1}}^{T_{4}} C_{P} \mathrm{~d} T=\dot{m}_{T}\left(0.835 \times 10^{-11} T^{3}\right. \\
& \quad+0.5816 \times 10^{-7} T^{2.5}-2.123 \times 10^{-7} T^{2} \\
& \quad+2.108 \times 10^{-5} T^{1.5}+1.3303 T+2.024 \times 10^{4} T^{-0.5} \\
& \quad-3.063 \times 10^{5} T^{-1}+1.106 \times\left. 10^{7} T^{-2}\right|_{T_{2}} ^{T_{3}}, \\
& P_{l}=\mu \bar{S}_{P}^{2}=\left(Z+0.048 N+0.4 \bar{S}_{P}^{2}\right) V_{s} N / 1200,
\end{aligned}
$$

where $Z$ is a constant relation to friction [10] and its minimum value is taken as 75 , where $\mu$ is a coefficient of friction which considers the global losses, $\bar{s}_{P}$ is mean piston velocity which is given as

$$
\bar{s}_{P}=L \times N / 30,
$$

where $L$ and $N$ are stroke length $[\mathrm{m}]$ and engine speed [rpm]. $\dot{Q}_{f}$ is the total heat potential of the injected fuel and it is given as below

$$
\dot{Q}_{f}=\dot{m}_{f} H_{u},
$$

where $H_{u}$ is lower heat value (LHV). $\dot{m}_{f}$ is timedependent fuel mass and it can be expressed as follows:

$$
\dot{m}_{f}=m_{f} N / 120,
$$

where $m_{f}$ is fuel mass per cycle $[\mathrm{kg}] . \dot{Q}_{f, c}$ is heat released by combustion, $\dot{Q}_{h t}$ is the heat loss by heat transfer into cylinder wall and they are given as below

$$
\begin{aligned}
& \dot{Q}_{f, c}=\eta_{c} \dot{m}_{f} H_{u}, \\
& \dot{Q}_{h t}=h_{t r} A_{c y l}\left(T_{m e}-T_{W}\right)= \\
& \quad h_{t r} A_{c y l}\left(T_{2}+T_{3}-2 T_{W}\right) / 2,
\end{aligned}
$$

Where, $\eta_{c}$ is combustion efficiency. It can be written as below $[7,8,26]$ :

$$
\eta_{c}=-1.44738+4.18581 / \phi-1.86876 / \phi^{2} .
$$

$\phi$ is equivalence ratio and it can be written as below

$$
\phi=\left(m_{f} / m_{a}\right) / F_{s t},
$$

where $m_{a}$ is air mass per cycle $[\mathrm{kg}] . F_{s t}$ is stoichiometric fuel-air ratio and they are given as follows:

$$
\begin{aligned}
& m_{a}=\rho_{a} V_{a}=\rho_{a}\left(V_{T}-V_{r g}\right), \\
& V_{T}=V_{s}+V_{c}=V_{s} r /(r-1), \\
& V_{c}=\frac{V_{T}}{r}=\frac{\pi d^{2} L}{4(r-1)} \\
& F_{s t}=\varepsilon(12.01 \alpha+1.008 \beta+16 \gamma+14.01 \delta) / 28.85, \\
& \rho_{a}=f\left(T_{1}, P_{1}\right),
\end{aligned}
$$

where $V_{T}, V_{a}, V_{r g}, V_{s}$, and $V_{c}$ are volume of total cylinder, air, residual gas, stroke and clearance.

$\rho_{r g}$ is density of residual gas which is given as below

$$
\rho_{r g}=f\left(T_{m i x}, P_{1}\right) \text {. }
$$

$T_{m i x}$ is average temperature of air-steam mixture. They are given as below

$$
T_{m i x}=\frac{\dot{m}_{a} T_{1} R_{a}+\dot{m}_{r g} T_{1} R_{r g}}{\dot{m}_{a} R_{a}+\dot{m}_{r g} R_{r g}} .
$$

$R_{a}$ and $R_{r g}$ are gas constants of air and residual gas. Their values are taken as $0.287 \mathrm{~kJ} /(\mathrm{kg} \mathrm{K})$.

The compression ratio $r$ is given as

$$
r=V_{1} / V_{2},
$$

where $f$ stands for function. The functional statements are acquired by using EES software [40]. The fuel type used in the model is gasoline and its chemical formula is given as $\mathrm{C}_{7} \mathrm{H}_{17}$ [41].

$\alpha, \beta, \gamma, \delta$ are atomic numbers of carbon, hydrogen, oxygen, nitrogen in fuel, respectively. $\varepsilon$ is molar fuel-air ratio [42]:

$$
\varepsilon=0.21 /\left(\alpha-\frac{\gamma}{2}+\frac{\beta}{4}\right),
$$

where $h_{t r}$ is heat transfer coefficient and it is stated 
as [42]:

$$
h_{t r}=130 V_{T}^{-0.06} P_{1}^{0.8} T_{m i x}^{0.4}\left(\bar{s}_{P}+1.4\right)^{0.8},
$$

where $\dot{m}_{T}, \dot{m}_{a}, \dot{m}_{r g}$ and $A_{c y l}$ are flow rate of total charge $[\mathrm{kg} / \mathrm{s}]$, air $[\mathrm{kg} / \mathrm{s}]$, residual gas $[\mathrm{kg} / \mathrm{s}]$ and total heat transfer area $\left[\mathrm{m}^{2}\right]$, respectively, they are given as:

$$
\begin{aligned}
& \dot{m}_{T}=\dot{m}_{a}+\dot{m}_{f}+\dot{m}_{r g}, \\
& \dot{m}_{a}=m_{a} N / 120=\dot{m}_{f} F_{s t} / \phi, \\
& \dot{m}_{r g}=m_{r g} N / 120=\dot{m}_{a} R G F, \\
& A_{c y l}=\pi d L r /(r-1)+\pi d^{2} / 2,
\end{aligned}
$$

where $m_{s}$ and $m_{r g}$ are air masses per cycle [kg]. RGF is the residual gas fraction. $r$ and $d$ are compression ratio and cylinder bore $[\mathrm{m}]$, respectively. $T_{W}$ and $T_{m e}$ are cylinder wall temperature and average combustion temperature and $C_{V}$ and $C_{P}$ are constant volume and constant pressure specific heats, they can be stated as follows [38]:

$$
\begin{aligned}
& C_{P}=2.506 \times 10^{-11} T^{2}+1.454 \times 10^{-7} T^{1.5} \\
& \quad-4.246 \times 10^{-7} T+3.162 \times 10^{-5} T^{0.5}+1.3301 \\
& -1.512 \times 10^{4} T^{-1.5}+3.063 \times 10^{5} T^{-2} \\
& -2.212 \times 10^{7} T^{-3}, \\
& C_{V}=C_{P}-R .
\end{aligned}
$$

The equations for reversible adiabatic processes (1-2s) and $(3-4 \mathrm{~s})$ are respectively as follows [43]:

$$
\begin{aligned}
& C_{V_{1}} \times \ln \left|\frac{T_{2 s}}{T_{1}}\right|=R \ln |r|, \\
& C_{V_{2}} \times \ln \left|\frac{T_{4 s}}{T_{3}}\right|=R \times \ln \left|\frac{1}{r}\right|,
\end{aligned}
$$

where

$$
\begin{aligned}
& C_{V_{1}}=2.506 \times 10^{-11} T_{2 s 1}^{2}+1.454 \times 10^{-7} T_{2 s 1}^{1.5} \\
& \quad-4.246 \times 10^{-7} T_{2 s 1}+3.162 \times 10^{-5} T_{2 s 1}^{0.5}+1.0433 \\
& \quad-1.512 \times 10^{4} T_{2 s 1}^{-1.5}+3.063 \times 10^{5} T_{2 s 1}^{-2} \\
& \quad-2.212 \times 10^{7} T_{2 s 1}^{-3}, \\
& C_{V_{2}}=2.506 \times 10^{-11} T_{4 s 3}^{2}+1.454 \times 10^{-7} T_{4 s 3}^{1.5} \\
& \quad-4.246 \times 10^{-7} T_{4 s 3}+3.162 \times 10^{-5} T_{4 s 3}^{0.5}+1.0433 \\
& \quad-1.512 \times 10^{4} T_{4 s 3}^{-1.5}+3.063 \times 10^{5} T_{4 s 3}^{-2} \\
& \quad-2.212 \times 10^{7} T_{4 s 3}^{-3}, \\
& T_{2 s 1}=\frac{T_{2 s}-T_{1}}{\ln T_{2 s} / T_{1}}, \quad T_{4 s 3}=\frac{T_{4 s}-T_{3}}{\ln T_{4 s} / T_{3}}, \\
& \beta=P_{3} / P_{2}=T_{3} / T_{2} .
\end{aligned}
$$

$\beta$ is named as pressure ratio. For irreversible conditions, $T_{2}$ and $T_{4}$ could be written as below

$$
\begin{aligned}
& T_{2}=\frac{T_{2 S}+T_{1}\left(\eta_{C}-1\right)}{\eta_{C}}, \\
& T_{4}=T_{3}+\eta_{E}\left(T_{4 S}-T_{3}\right),
\end{aligned}
$$

where $\eta_{C}$ and $\eta_{E}$ are isentropic efficiencies for the com- pression and expansion processes, respectively. In this study, the other dimensionless engine design parameters used in the analysis are cycle temperature ratio $(\alpha)$ and cycle pressure ratio $(\lambda)$. They may be expressed respectively as

$$
\begin{aligned}
& \alpha=\frac{T_{\max }}{T_{\min }}=\frac{T_{3}}{T_{1}}=\frac{\lambda}{r}=1+\frac{r^{k-1}-1}{\eta_{C}}, \\
& \lambda=P_{\max } / P_{\min }=P_{3} / P_{1} .
\end{aligned}
$$

In this study, HTL, FL, ICL, and EOL are given as follows:

$$
\begin{gathered}
L_{h t}=\frac{\dot{Q}_{h t}}{\dot{Q}_{f u e l}} \times 100, \quad L_{e x}=\frac{\dot{Q}_{\text {out }}}{\dot{Q}_{f u e l}} \times 100, \\
L_{f r}=\frac{P_{u}}{\dot{Q}_{\text {fuel }}} \times 100, \quad L_{i c}=\left(1-\eta_{C}\right) \times 100 .
\end{gathered}
$$

\section{Results and discussion}

In this study, a finite time thermodynamic model has been used to evaluate EE, EP, and EDP of an AC engine. Parametrical studies have been performed to investigate the engine design and running parameters on the performance of $\mathrm{AC}$ engine. The engine properties are given in Table I.

Engine properties.

TABLE I

\begin{tabular}{l|c}
\hline \hline Specification & Value \\
\hline bore $[\mathrm{mm}]$ & 72 \\
stroke $[\mathrm{mm}]$ & 62 \\
cylinder number & 2 \\
stroke volume $\left[\mathrm{dm}^{3}\right]$ & 0.54 \\
maximum power $[\mathrm{kW}]$ & 15 \\
compression ratio & 10.7 \\
maximum speed $[\mathrm{rpm}]$ & 3600 \\
coolant & water
\end{tabular}

The variation of EE, EP, and EPD are demonstrated with respect to compression ratio (r) in the following figures.

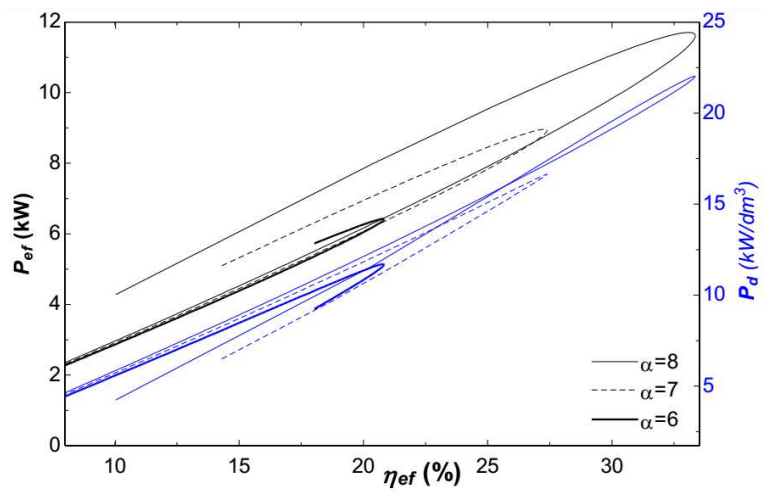

Fig. 2. The variation of $P_{e f}-P_{d}-\eta_{e f}$ with respect to $\alpha$.

Figure 2 shows the effects of cycle temperature ratio on the performance parameters. The maximum EE, EP, and 


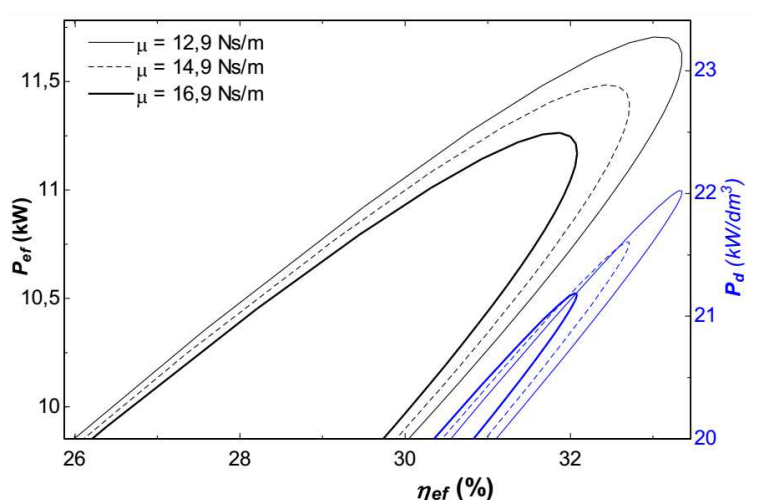

Fig. 3. The variation of $P_{e f}-P_{d}-\eta_{e f}$ with respect to $\mu$.

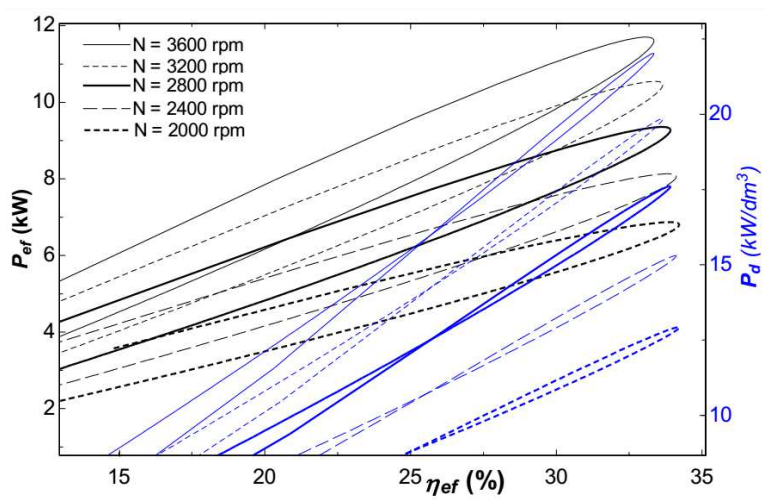

Fig. 4. The variation of $P_{e f}-P_{d}-\eta_{e f}$ with respect to $N$.

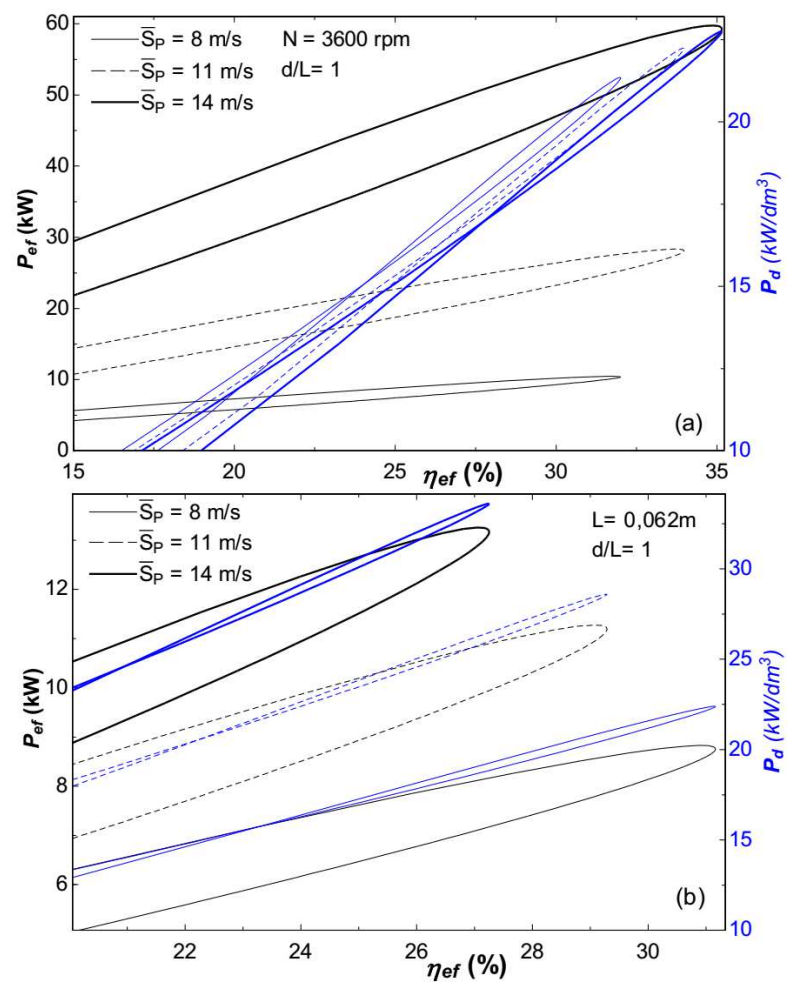

Fig. 5. The variation of $P_{e f}-P_{d}-\eta_{e f}$ with respect to $\bar{S}_{P}$ at constant (a) $N$, (b) $L$.

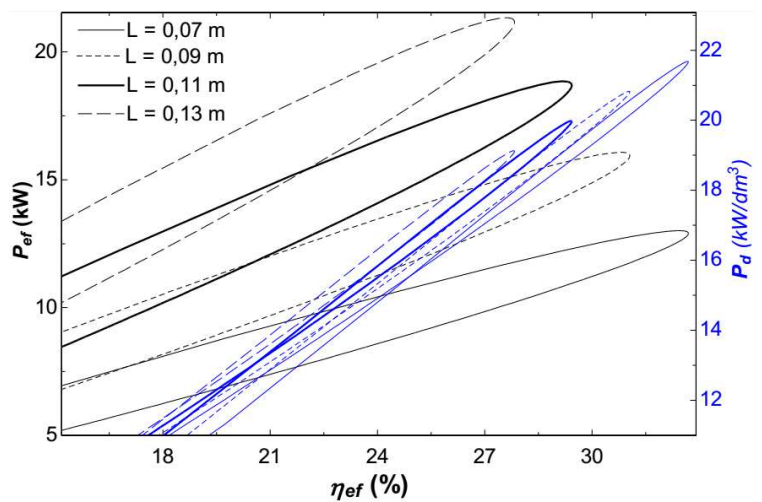

Fig. 6. The variation of $P_{e f}-P_{d}-\eta_{e f}$ with respect to $L$.
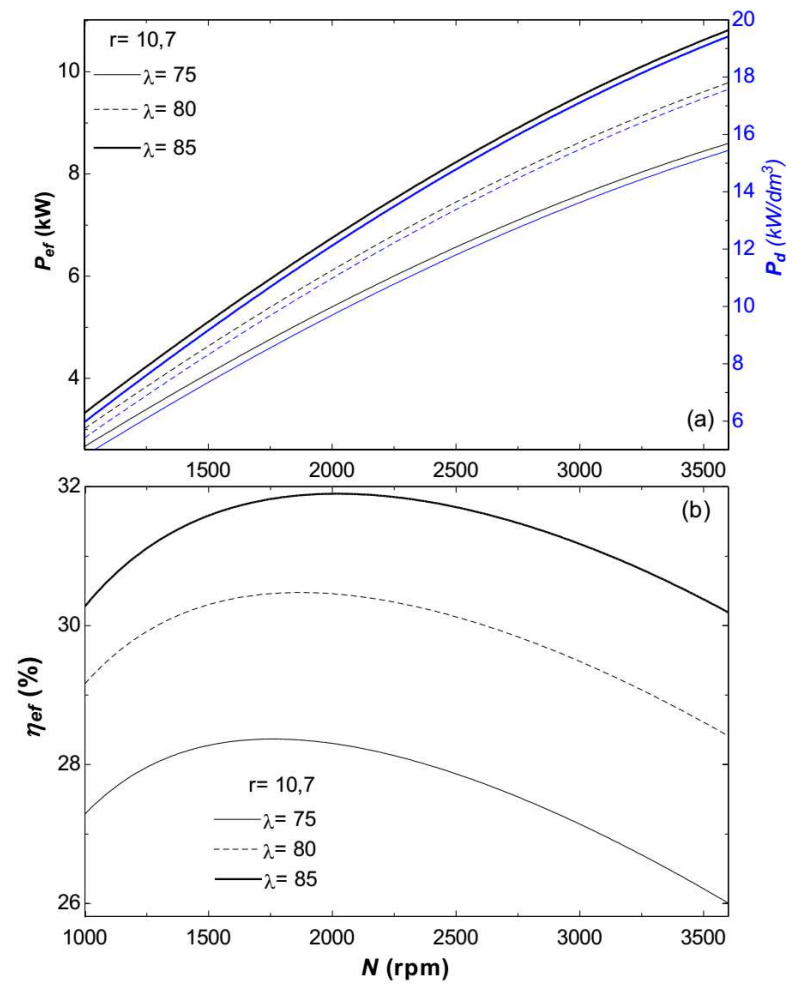

Fig. 7. The variation of (a) $P_{e f}-P_{d}$ and (b) $\eta_{e f}$ with respect to $N$ and $\lambda$.

EPD increase with increase of cycle temperature ratio owing to more energy input into cylinder. It is clear from the figure that the amplitude of power density is lower than that of effective power.

Figure 3 demonstrates the effects of friction coefficient on the engine performance. The friction coefficient is directly related to lubrication oil and friction surfaces. Friction losses increase with increase of the friction coefficient, hence maximum EE, EP, and EPD decrease.

Figure 4 illustrates the effects of engine speed on the performance characteristics. As expected, the EP and EPD raise with enhancing engine speed. However, the $\mathrm{EE}$ is lower at low engine speeds compared to that at high engine speeds. At high engine speeds, there are 

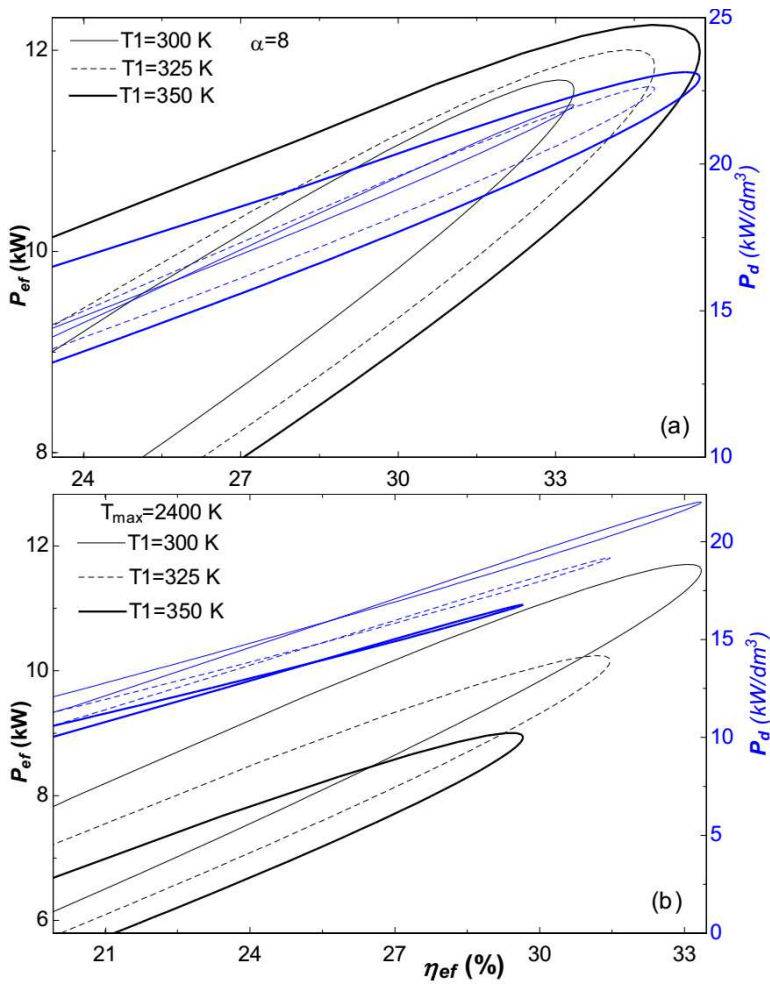

Fig. 8. The variation of $P_{e f}-P_{d}-\eta_{e f}$ with respect to $T 1$ at constant (a) $\alpha$ and (b) $T_{\max }$.

no considerable differences between maximum effective efficiencies as the friction losses rise with rising engine speeds. Increase ratio of fuel's energy slightly is higher compared to that of the EP and EPD.

Figure 5a and $\mathrm{b}$ illustrates the effects of average piston speed on the performance characteristics. In these figures, two conditions are determined as constant engine speed condition (the 1. condition) and constant stroke length condition (the 2. condition). It is clear that the $\mathrm{EP}, \mathrm{EPD}$, and EE increase together with rising average piston speed at the 1 . condition since engine dimensions (stroke length and bore) enhance. However, while the EE decreases, the EP and EPD increase with increase of average piston speed at the 2 . condition as engine speed increases. It is obvious that power density change of the 2 . condition is grater compared to that of 1 . condition since engine dimensions increase with increase of effective power.

Figure 6 shows the effects of stroke length on the engine performance. It is clear from the figure that the EP increases while the EE and EPD decrease with increase of stroke length. The main reason of this result is that the friction losses and engine dimensions increase with respect to stroke length. Although engine power increases, engine dimensions more increase. Also, we can see that the ratio of power change is higher than that of power density.

Figure 7a and $\mathrm{b}$ demonstrates the effects of cycle pressure ratio and engine speed on the engine performance for constant compression ratio condition. Cycle pressure
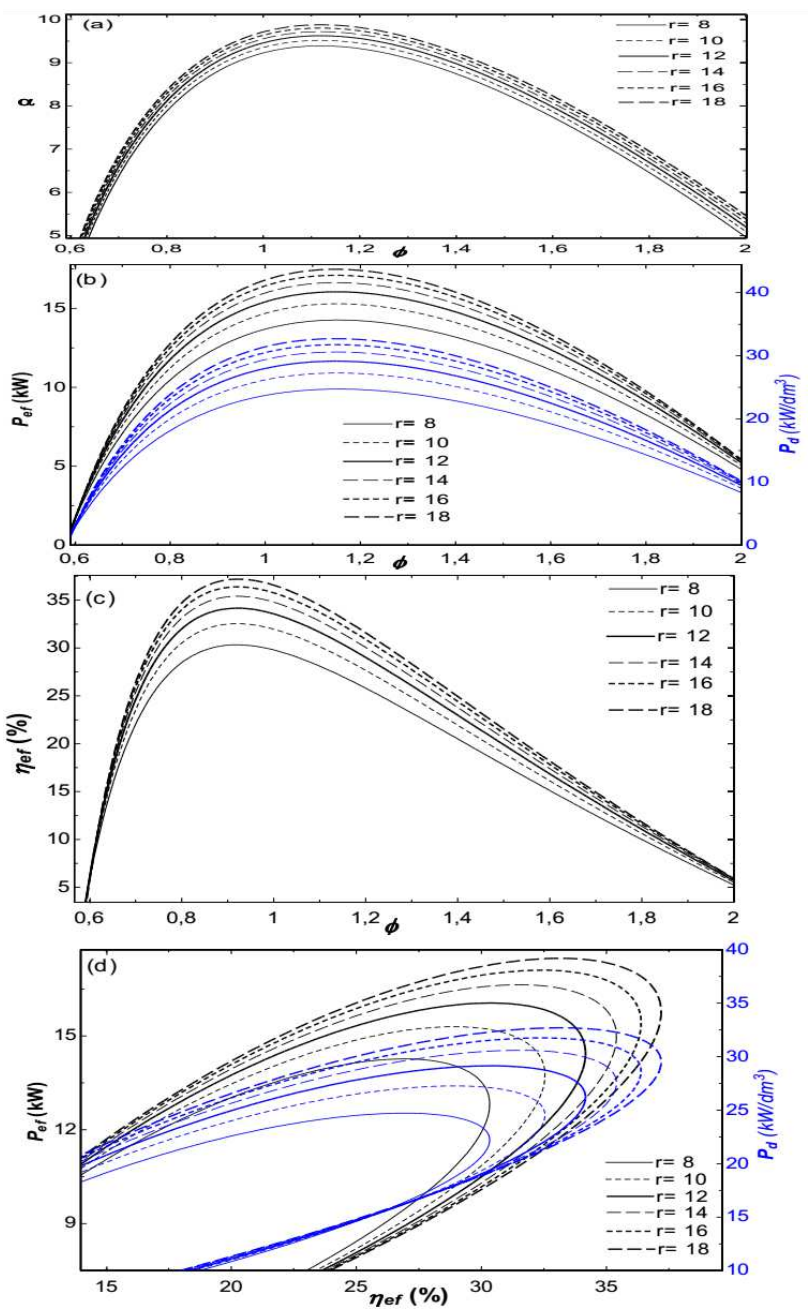

Fig. 9. The variation of (a) $\alpha$, (b) $P_{e f}-P_{d}$, (c) $\eta_{e f}$ and (d) $P_{e f}-\eta_{e f}$ with respect to $r$ and $\phi$.

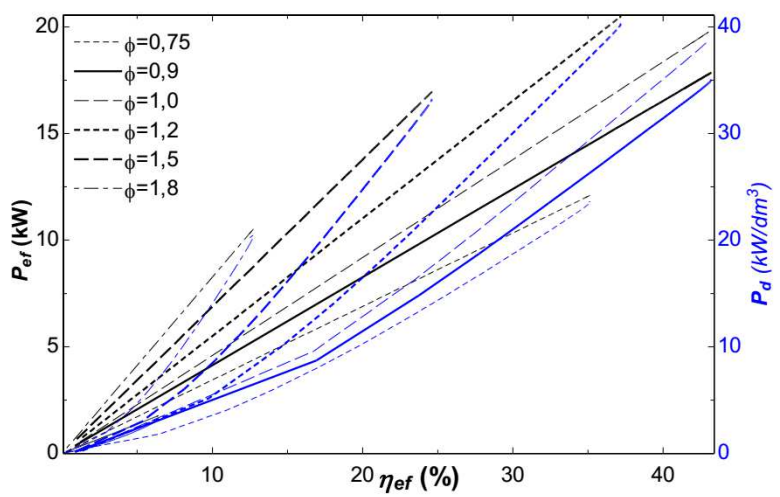

Fig. 10. The variation of $P_{e f}-P_{d}-\eta_{e f}$ with respect to $\phi$.

ratio has positive effect on the engine performance parameters. They increase with enhancing cycle pressure ratio. The engine power and power density increase with increase of engine speed. However, the EE rises to a specified value of engine speed and then decreases. It is clear that optimum engine speed which provides the maximum EE rises with enhancing cycle pressure ratio. 


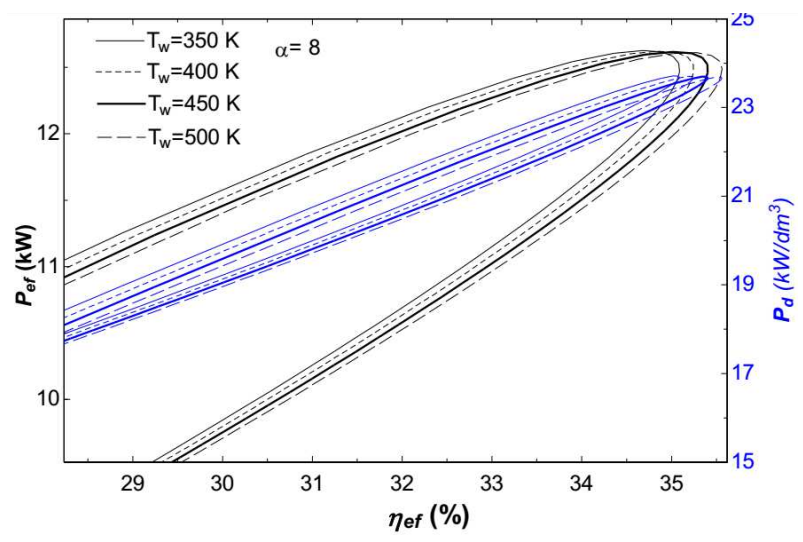

Fig. 11. The variation of $P_{e f}-P_{d}-\eta_{e f}$ with respect to $T_{W}$.

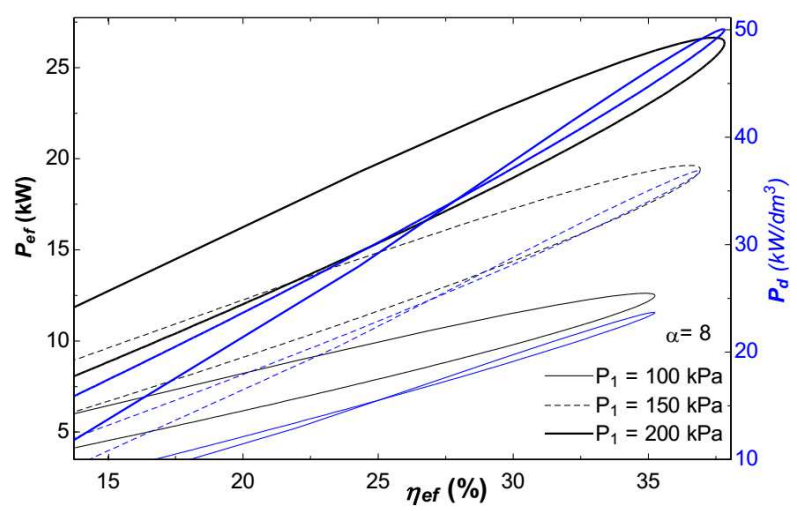

Fig. 12. The variation of $P_{e f}-P_{d}-\eta_{e f}$ with respect to $P_{1}$.

Figure $8 \mathrm{a}$ and $\mathrm{b}$ shows the effects of intake temperature on the engine performance. Two main conditions have been described as constant cycle temperature ratio condition (the 1 . condition) and constant maximum combustion temperature condition (the 2 . condition) in these figures. At the 1. condition, the maximum EP, EPD, and EE increase while intake temperature increases since maximum combustion temperature and energy input increase. However, the maximum engine performance di-

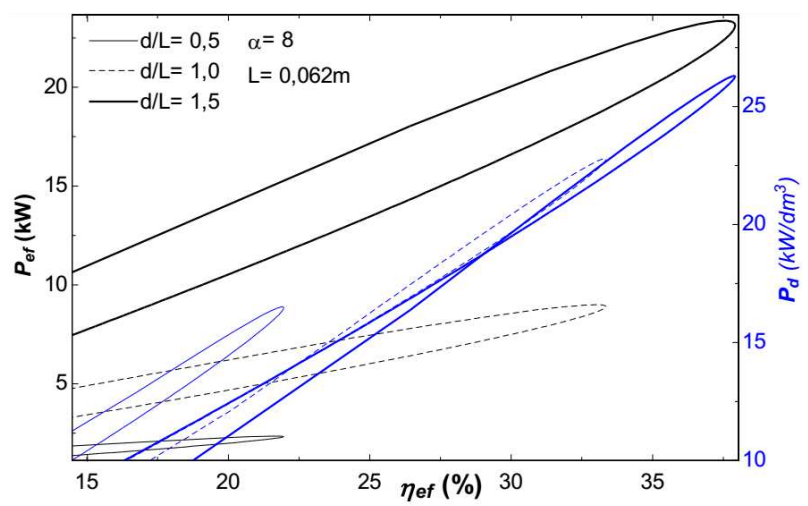

Fig. 13. The variation of $P_{e f}-P_{d}-\eta_{e f}$ with respect to $d / L$.

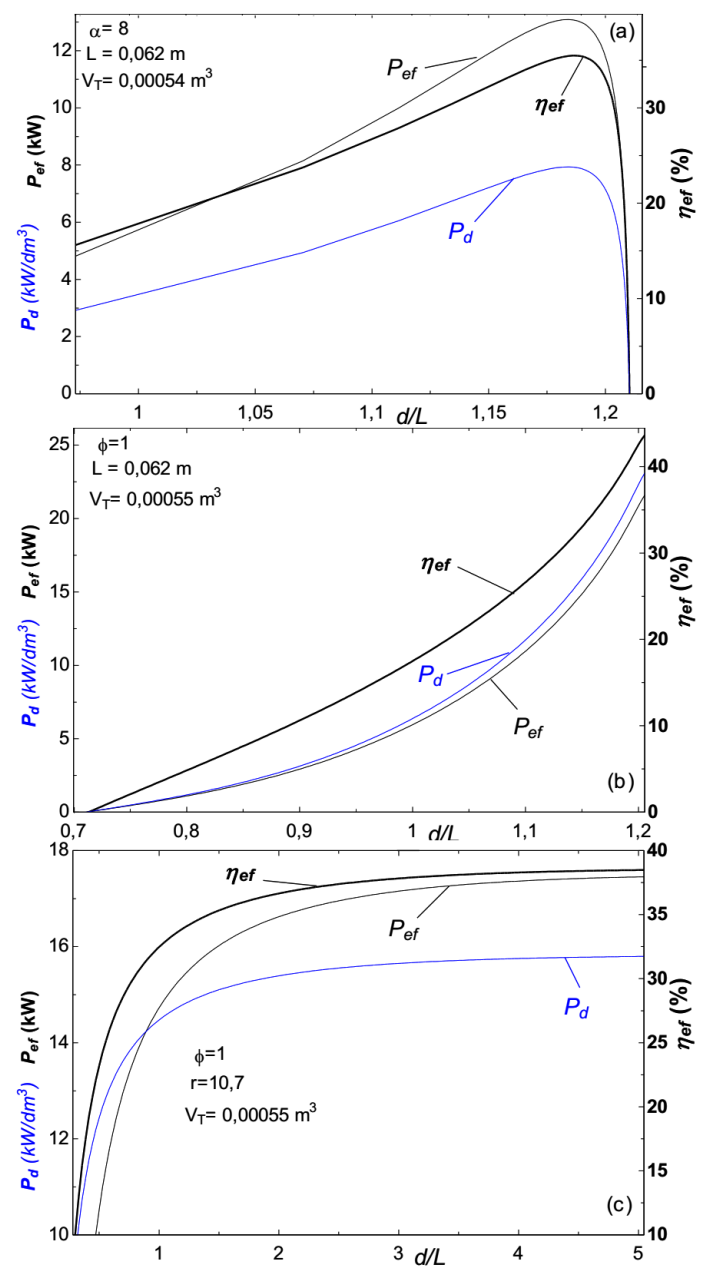

Fig. 14. The effects of $d / L$ on $P_{e f}-P_{d}-\eta_{e f}$ variation at constant (a) $\alpha$ and $L$, (b) $\phi$ and $L$, (c) $\phi$ and $r$.

minishes with enhancing air inlet temperature at the 2 . condition as air mass in the cylinder minimizes.

Figure $9 \mathrm{a}-\mathrm{d}$ illustrates the influences of compression ratio and equivalence ratio on the cycle temperature ratio and performance characteristics. As can be seen from the figure, cycle temperature ratio, EP, EPD, and EE rise with enhancing compression ratio. However, they maximize to a determined value and then begin to abate with respect to rising equivalence ratios. There are optimum values of equivalence ratio which provides maximum cycle temperature ratio, EP, EPD, and EE. Their optimum values are attained at different equivalence ratios. The highest values of cycle temperature ratio, EP and EPD are between 1 and 1.2 of equivalence ratio while the maximum value of $\mathrm{EE}$ is between 0.8 and 1 of that.

Figure 10 shows the influence of equivalence ratio on the performance characteristics. Similar to previous figures, the maximum EE, EP, and EPD increase to particular values of equivalence ratio and then begin to abate. The maximum effective efficiency is seen when equivalence ratio is equal to 0.9 while the maximum effective power is seen when equivalence ratio happens 1.2. 

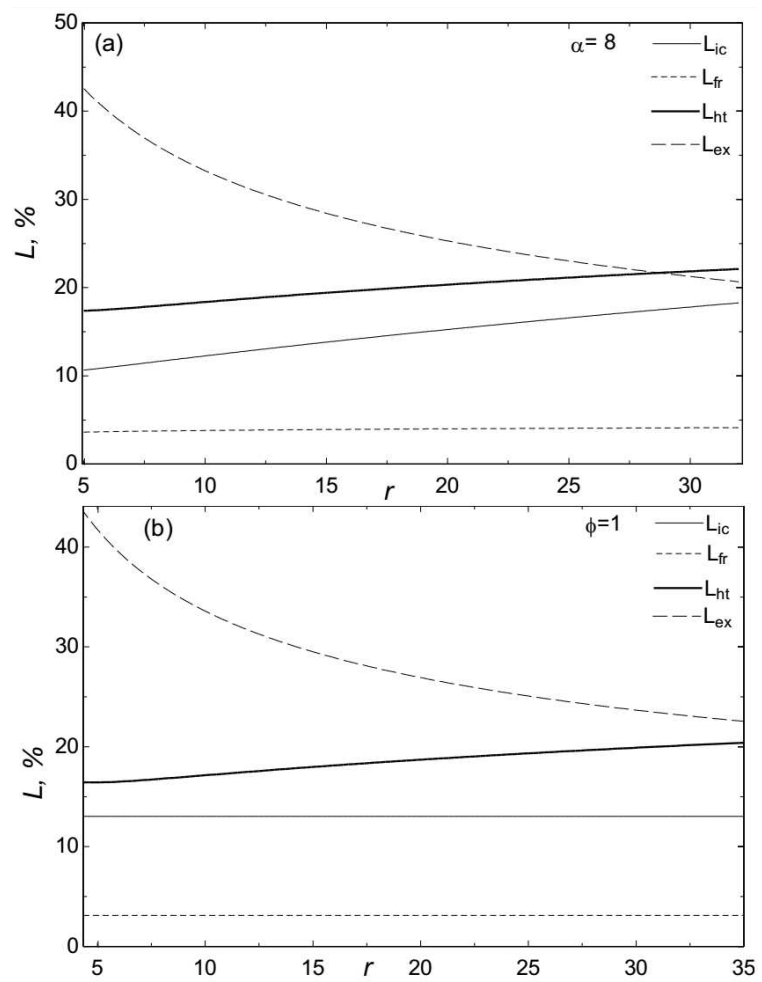

Fig. 15. The variation of energy loss percentages with respect to $r$ for constant (a) $\alpha$ and (b) $\phi$.

The effects of cylinder wall temperature on the performance characteristics is shown in Fig. 11. There are no considerable changes in maximum effective power and power density depends on cylinder wall temperature. However, maximum effective efficiency increases with increase of cylinder wall temperature as heat transfer loss decreases.

Figure 12 demonstrates the effect of air inlet pressure on the performance characteristics. It is known that more air mass is introduced into the cylinder at higher pressure conditions. Therefore, the performance characteristics rise with enhancing air inlet pressure.

The influence of bore/stroke ratio $(d / L)$ on the engine performance characteristics is shown in Fig. 13. It is obvious that the performance characteristics rise with rising $d / L$ owing to enhancing dimension of the engine.

Figure 14 shows the effects of $d / L$ on the engine performance at constant cylinder volume for different conditions. In this figures, three conditions are determined as constant cycle temperature ratio and stroke length condition (the 1 . condition), constant equivalence ratio and stroke length condition (the 2. condition), constant equivalence ratio and compression ratio condition (the 3 . condition). At the 1. condition, the EP, EPD, and EE maximize to a specified value and then begin to abate with rising $d / L$. At the 2 . and 3 . conditions, the EP, EPD and EE raise with enhancing $d / L$.

Figure 15 illustrates the effects of compression ratio on losses as fuel's energy. In order to investigate the energy losses, two conditions are determined as constant cycle temperature ratio condition (the 1 . condition) and constant equivalence ratio condition (the 2 . condition). Incomplete combustion losses $\left(L_{i c}\right)$ and heat transfer losses $\left(L_{h t}\right)$ increase whilst exhaust energy losses $\left(L_{e x}\right)$ decrease and friction losses $\left(L_{f r}\right)$ remain constant with rising compression ratio at the 1 . condition. Total cylinder volume and equivalence ratio change with respect to changing of compression ratio at this condition. However, $L_{i c}$ and $L_{f r}$ are constant, $L_{h t}$ increases and $L_{e x}$ minimizes with respect to rising compression ratio at the 2 . condition. $L_{i c}$ does not change at constant equivalence ratio because combustion efficiency is constant. Total cylinder volume increases with increasing compression ratio, hence $L_{h t}$ increases and $L_{e x}$ diminishes. $L_{f r}$ changes with respect to stroke length and engine speed which are constant at both of the conditions. Therefore, $L_{f r}$ does not change at the 2. condition due to constant fuel energy input. At the 1. condition, it increases since fuel energy input decreases with increase of compression ratio.

\section{Conclusion}

The influences of the design and running parameters on the performance characteristics of an AC engine are investigated by using a FTT model. A comprehensive parametrical study is conducted. The results showed that the $\mathrm{EP}, \mathrm{EPD}$, and EE rise with rising air inlet pressure, cycle pressure and temperature ratios. The performance characteristics diminish with friction coefficient. However, the EP, EPD, and EE raise with rising average piston speed for constant engine speed conditions, but, whilst the EP and EPD rise, the EE minimizes with rising average piston speed for constant stroke length conditions. While the EP and EPD increase, the EE reduces with rising stroke length and engine speed. The EP, EPD, and EE increase up to a determined value and then begin to minimize with rising equivalence ratio and compression ratio. The incomplete combustion losses (ICL) and heat transfer losses (HTL) raise, as exhaust output losses (EOL) decrease with augmenting compression ratio for constant cycle temperature ratio conditions. At this condition, FL is constant. However, the FL and ICL are constant, while EOL diminishes and HTL increase at the constant equivalence ratio conditions. The results have scientific value and they can be used as engineering approaches by engine designers.

\section{References}

[1] Y.Ge, L. Chen, F. Sun, C. Wu, Int. Commun. Heat Mass Transfer 32, 1045 (2005).

[2] Y. Ge, L. Chen, F. Sun, C. Wu, Int. J. Ambient Energy 26, 203 (2005).

[3] L. Chen, Y. Ge, F. Sun, C. Wu, Termotehnica 14, 24 (2010).

[4] L. Chen, Y. Ge, F. Sun, C. Wu, Int. J. Ambient Energy 32, 87 (2011).

[5] A. Al-Sarkhi, B.A. Akash, J.O. Jaber, M.S. Mohsen, E. Abu-Nada, Int. Commun. Heat Mass 29, 1159 (2002). 
[6] A. Al-Sarkhi, I. Al-Hinti, E. Abu-Nada, B. Akash, Int. Commun. Heat Mass 34, 897 (2007).

[7] R. Ebrahimi, Comput. Math. Appl. 62, 2169 (2011).

[8] R. Ebrahimi, Appl. Math. Model 36, 4073 (2012).

[9] G. Gonca, B. Sahin, Y. Ust, Energy 5, 285 (2013).

[10] G. Gonca, B. Sahin, Y. Ust, A. Parlak, Arab. J. Sci. Eng. 38, 383 (2013).

[11] G. Gonca, B. Sahin, Y. Ust, A. Parlak, A. Safa, J. Energy Inst. 88, 43 (2015).

[12] G. Gonca, B. Sahin, Y. Ust, J. Thermophys. Heat Transf. 29, 678 (2015).

[13] G. Gonca, B. Sahin, Y. Ust, A. Parlak, Appl. Therm. Eng. 85, 9 (2015).

[14] G. Gonca, B. Sahin, Appl. Therm. Eng. 105, 566 (2016).

[15] G. Gonca, B. Sahin, A. Parlak, Y. Ust, V. Ayhan, I. Cesur, Energy 78, 266 (2014).

[16] G. Gonca, B. Sahin, A. Parlak, Y. Ust, V. Ayhan, I. Cesur, Appl. Energy 138, 11 (2015).

[17] G. Gonca, B. Sahin, A. Parlak, V. Ayhan, I. Cesur, S. Koksal, Energy 93, 795 (2015).

[18] Y. Ust, F. Arslan, I. Ozsari, M. Cakir, Energy 90, $552(2015)$.

[19] G. Gonca, B. Sahin, Appl. Math. Model. 40, 3764 (2016).

[20] E.Dobrucali, Energy 103, 119 (2016).

[21] A. Mousapour, A. Hajipour, M.M. Rashidi, N. Freidoonimehr, Energy 94, 100 (2016).

[22] P.Y. Wang, S.S. Hou, Energy Convers. Manage. 46 2637 (2005).

[23] Y. Ge, L. Chen, F. Sun, C. Wu, Appl. Energy 83, 1210 (2006)

[24] J.C. Lin, S.S. Hou, Appl. Energy 84, 904 (2007).
[25] J. Benajes, J.R. Serrano, S. Molina, R. Novella, Energy Convers. Manage. 50, 174 (2009).

[26] R. Ebrahimi, Math. Comput. Model. 53, 1289 (2011).

[27] J. Zhao, M. Xu, M. Li, B. Wang, S. Liu, Appl. Energy 92, 492 (2012).

[28] M.H. Gahruei, H.S. Jeshvaghani, S. Vahidi, L. Chen, Appl. Math. Model. 37, 7319 (2013).

[29] J. Zhao, M. Xu, Appl. Energy 71, 335 (2013).

[30] A. Mozaffari, A. Ramiar, A. Fathi, Swarm Evolut. Comput. 12, 74 (2013).

[31] P. Capaldi, Appl. Therm. Eng. 71, 913 (2014).

[32] G. Gonca, B. Sahin, Sci. World J. 2014, 815787 (2014).

[33] G. Gonca, Energy Convers. Manage. 111, 205 (2016).

[34] G. Gonca, Appl. Math. Model. 40, 6725 (2016).

[35] R. Ebrahimi, Acta Phys. Pol. A 120, 384 (2011).

[36] R. Ebrahimi, Acta Phys. Pol. A 122, 645 (2012).

[37] R. Ebrahimi, Acta Phys. Pol. A 124, 29 (2013).

[38] G. Gonca, Polish Maritime Research 24, 86 (2017).

[39] Y. Ge, L. Chen, F. Sun, C. Wu, Appl. Energy 85, 618 (2008).

[40] F-Chart Software, EES Academic Professional Edition, 2014, V.9.701-3D.

[41] C.R. Ferguson, Internal Combustion Engines - Applied Thermosciences, Wiley, New York 1986.

[42] G. Hohenberg, Advanced Approaches for Heat Transfer Calculations, SAE Technical Paper 790825, 61 (1979).

[43] J. Lin, L. Chen, C. Wu, F. Sun, Int. J. Energy Res. 23, 765 (1999). 